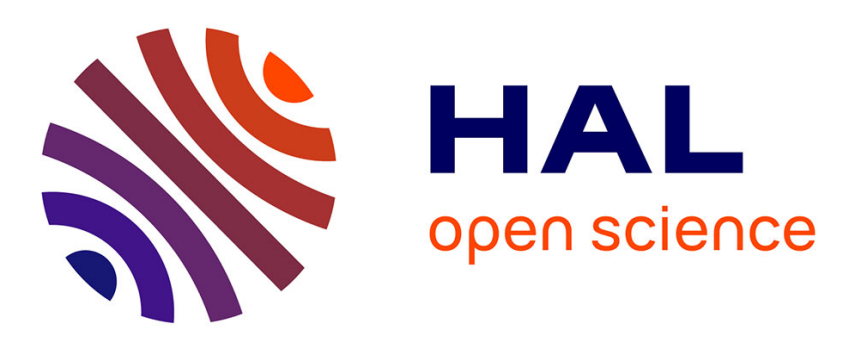

\title{
Significant dust simulation differences in nudged and climatological operation mode of the AGCM ECHAM
}

\author{
C. Timmreck, M. Schulz
}

\section{To cite this version:}

C. Timmreck, M. Schulz. Significant dust simulation differences in nudged and climatological operation mode of the AGCM ECHAM. Journal of Geophysical Research: Atmospheres, 2004, 109 (D13), pp.n/a-n/a. 10.1029/2003JD004381 . hal-03129704

\section{HAL Id: hal-03129704 \\ https://hal.science/hal-03129704}

Submitted on 3 Feb 2021

HAL is a multi-disciplinary open access archive for the deposit and dissemination of scientific research documents, whether they are published or not. The documents may come from teaching and research institutions in France or abroad, or from public or private research centers.
L'archive ouverte pluridisciplinaire HAL, est destinée au dépôt et à la diffusion de documents scientifiques de niveau recherche, publiés ou non, émanant des établissements d'enseignement et de recherche français ou étrangers, des laboratoires publics ou privés. 


\title{
Significant dust simulation differences in nudged and climatological operation mode of the AGCM ECHAM
}

\author{
C. Timmreck \\ Max-Planck Institut für Meteorologie, Hamburg, Germany
}

M. Schulz

Laboratoire des Sciences du Climat et de l'Environnement, CEA/CNRS, Gif-sur-Yvette, France

Received 25 November 2003; revised 6 April 2004; accepted 13 May 2004; published 7 July 2004.

[1] The geographical distribution and the seasonal variability of soil dust aerosol have been investigated with the climate model ECHAM4. Two experiments have been performed: a climatological with prescribed climatological sea surface temperatures (CLIM) and a nudged where the model is forced by ECMWF Reanalysis data of the particular years 1986-1991 (NUDGE). The mean geographical distribution and the seasonal variability of mineral dust alter between the different modes of operation of the climate model. Largest deviations occur in Northern Hemisphere winter and are related to the overestimation and the mislocation of the Azores high in ECHAM4. The Saharan dust plume is shifted farther north in CLIM compared to NUDGE and Meteosat satellite observations with significant implication for the cross-Atlantic transport. In the dust source regions the wind speed distribution is slightly shifted and creates a twofold difference in total dust emissions. Our results indicate that the mode of operation of the climate model seems to be as important as the interannual variability of the dust cloud by climate variations alone. INDEX TERMS: 0305 Atmospheric Composition and Structure: Aerosols and particles $(0345,4801) ; 0322$ Atmospheric Composition and Structure: Constituent sources and sinks; 0330 Atmospheric Composition and Structure: Geochemical cycles; 0368 Atmospheric Composition and Structure: Troposphere - constituent transport and chemistry; KEYWORDS: aerosols, mineral dust, tracer modeling, global modeling

Citation: Timmreck, C., and M. Schulz (2004), Significant dust simulation differences in nudged and climatological operation mode of the AGCM ECHAM, J. Geophys. Res., 109, D13202, doi:10.1029/2003JD004381.

\section{Introduction}

[2] Mineral dust affects the climate system in various ways; by changing the radiation balance [e.g., Tegen and Lacis, 1996; Sokolik and Toon, 1996; Claquin et al., 1998], the atmospheric composition [e.g., Dentener et al., 1996; Underwood et al., 2001], the productivity of marine and terrestrial ecosystems [e.g., Martin, 1991; Chadwick et al., 1999], and cloud and aerosol microphysics [e.g., Wurzler et al., 2000; Korhonen et al., 2003]. Consideration of soil dust in global models has therefore been addressed by several groups over the last decades [e.g., Ginoux et al., 2001; Perlwitz et al., 2001; Woodward, 2001; Tegen et al., 2002; Luo et al., 2003].

[3] In an accompanying paper by C. Timmreck and M. Schulz (manuscript in preparation, 2004), here referenced as TS04A, we have introduced our global dust model for the ECHAM4 climate model and validated it with satellite and surface observations. It has been demonstrated that a monomodal lognormal aerosol size distribution

Copyright 2004 by the American Geophysical Union. 0148-0227/04/2003JD004381\$09.00 initially around a mass mean diameter of $2.5 \mu \mathrm{m}$ and a standard deviation of $\sigma=2$ is suitable to simulate the longrange transport of Saharan dust over the Atlantic. Dust from Australia and southern America sources and dust transport from Asia in Northern Hemisphere spring are, however, underpredicted in our model. The dust simulations presented in TS04A have been performed in a nudged mode of the climate model. The climate model we are using (ECHAM) can be operated in different modes of operation, such as in a nudged mode and in a climatological mode. "Nudging" is a relaxation technique, which uses observed meteorology to force the evolution of transport in the course of time. A big advantage of a nudged simulation is that it can be directly compared to observations, while for climate change experiments the model has to run freely in the climate mode. The purpose of this study is to investigate how the mean geographical distribution and seasonal variability of mineral dust alters between the different modes of operation of the climate model. Such differences can point to errors in estimating the climate effect of dust using a general circulation model in climate change experiments.

[4] A brief description of the model is given in section 2 . In section 3 the model experiments are compared with 
respect to the global budget, the geographical distribution and the seasonal variability. Section 4 summarizes the results and concludes the paper.

\section{Model Description}

\subsection{Circulation Model}

[5] We use the Hamburg climate model ECHAM4 [Roeckner et al., 1996], which with 19 layers extends from the surface to $10 \mathrm{hPa}$. The ECHAM4 is run with a spectral triangular truncation at wavenumber 42 (T42) resolution. The prognostic variables are vorticity, divergence, surface pressure, temperature, water vapor, cloud water and cloud ice. The cloud microphysics scheme is based on Lohmann and Roeckner [1996]. Physical processes and nonlinear terms are calculated on a Gaussian longitude-latitude grid with a nominal resolution of $2.85^{\circ} \times 2.85^{\circ}(\approx 256 \mathrm{~km} \times$ $256 \mathrm{~km}$ ). In the model the Spitfire transport scheme [Rasch and Lawrence, 1998] is applied for the tracer transport. The model time step is $24 \mathrm{~min}$ for both the dynamics and the physics.

\subsection{Dust Model}

[6] The mineral dust is prescribed by 2 prognostic variables: mass and number concentration. For the source formulation we have used a function dependent on soil type and FAO soil map which has been developed by Claquin [1999] based on Marticorena and Bergametti [1995]. The emission flux is parameterized as a function of the $10 \mathrm{~m}$ wind speed, source strength factor, clay content and the threshold velocity of wind erosion. While the threshold velocity is varying spatially, the source strength is adjusted for several larger regions, so that simulated aerosol optical thickness represents observed aerosol optical depth fields from the TOMS satellite. A detailed description of the source is given in TSO4A and in Balkanski et al. [2003]. At the source the size distribution is imposed with a mass mean diameter of $2.5 \mu \mathrm{m}$ and a standard deviation of $\sigma=2$ according to observations and sensitivity studies [Schulz et al., 1998]. The mass mean diameter is allowed to vary during the time evolution of the aerosol while the standard deviation is kept constant. The calculation of the time evolution of the size distribution and the dust cloud includes: stratiform and convective scavenging, sedimentation and turbulent dry deposition. The optical thickness of the dust aerosol at $\lambda=0.55 \mu \mathrm{m}$ was calculated offline from the dust mass and number distribution as described by Schulz et al. [1998].

\subsection{Experimental Setup}

[7] As introduced above, we performed two different experiments, a climatological (CLIM) and a nudged experiment (NUDGE). In the CLIM experiment the model is integrated for 10 years after a 6-month spin-up. The sea surface and surface temperature (SST) is prescribed by monthly mean data using the AMIP SST [Gates et al., 1998].

[8] In the NUDGE experiment the model is forced by ECMWF Reanalysis data ERA 15 . To do so, we apply a data assimilation technique based on Newtonian relaxation [Hoke and Anthes, 1976; Krishnamurti et al., 1991]. This "nudging" technique forces a prognostic model variable A, toward its observed values by adding a nonphysical term to the model equations [Jeuken et al., 1996]:

$$
\frac{\partial \mathrm{A}}{\partial \mathrm{t}}=\mathrm{F}^{\mathrm{m}}(\mathrm{A}, \mathrm{t})+\mathrm{K}_{\mathrm{N}}(\mathrm{A}, \mathrm{t})\left(\mathrm{A}^{\mathrm{obs}}(\mathrm{t})-\mathrm{A}(\mathrm{t})\right),
$$

where $\mathrm{A}^{\text {obs }}(\mathrm{t})$ is the observational value, $\mathrm{K}_{\mathrm{N}}(\mathrm{A}, \mathrm{t})$ the relaxation coefficient, and $\mathrm{F}^{\mathrm{m}}$, the model forcing term, which describes the physical and dynamical evolution of $A(t)$. In these simulations the relaxation coefficients $K_{N}$ (inverse ot the relaxtion time) are constant in time and space. The prognostic variables which are relaxed to observations, are temperature $\left(\mathrm{K}_{\mathrm{N}}=2.32 \cdot 10^{-4} \mathrm{~s}^{-1}\right)$, vorticity $\left(\mathrm{K}_{\mathrm{N}}=9.29 \cdot 10^{-4} \mathrm{~s}^{-1}\right)$, divergence $\left(\mathrm{K}_{\mathrm{N}}=1.16\right.$. $\left.10^{-4} \mathrm{~s}^{-1}\right)$ and the logarithm of the surface pressure $\left(\mathrm{K}_{\mathrm{N}}=\right.$ $\left.1.16 \cdot 10^{-5} \mathrm{~s}^{-1}\right)$. The relaxation coefficients are choosen to be relatively strong in order to keep the model fields close to the reanalysis data. Differences between the simulated $10 \mathrm{~m}$ wind field, for example, and the ERA 15 data are in the tropics and subtropics within 10\%. The ECMWF reanalysis data are six hourly forecast data of temperature, vorticity, divergence and surface pressure, which are linearly interpolated in order to obtain values at every time step. So we calculate every $24 \mathrm{~min}$ a different value for each meteorological field, e.g., surface wind speed. In addition daily observed SSTs are prescribed based on ECMWF data. The idea of comparing satellite data for a continuous time period with model output requires an overlap of availability of ECMWF and Meteosat data. We have chosen the period 1986-1991 prior to the eruption of Mount Pinatubo. Among those years was a year with relative low dust load (1986) and a year with relative high dust content (1989). If not mentioned otherwise, results of the NUDGE experiment refer to the 6 years between 1986 and 1991 and those of the CLIM experiment to a period of 10 years.

\section{Comparison of the NUDGE and the CLIM Experiment}

[9] In this chapter, we investigate how the mean geographical distribution and the seasonal variability of mineral dust differ between NUDGE and CLIM. Information about possible differences between both modes of the climate model are important for the estimation of the climate effect of dust in climate change experiments. At first, we focus on differences in the global mineral dust budget and the importance of the high wind tail of the distribution of the instantaneous grid cell mean wind for dust emission. Then we discuss the global distribution of mineral dust simulated and in particular the position of the Atlantic plume. Finally, a more detailed analysis of the regional differences between both modes of operation of the climate model will be discussed based on interannual variability of emission, load and lifetime, the simulated vertical dust distribution and the cross-Atlantic transport.

\subsection{Global Budget}

[10] In Table 1 the global averaged annual budget of the two experiments is listed. The most striking difference between both experiments is the almost doubling of the emission flux in CLIM (913 Mt/yr) relative to NUDGE (500 Mt/yr). In consequence all deposition fluxes in CLIM 
Table 1. Global Mass Budget

\begin{tabular}{lcc}
\hline & \multicolumn{1}{c}{ CLIM } & NUDGE \\
\hline Source, Mt/yr & $913.1 \pm 132.0(100 \%)$ & $504.2 \pm 19.1(100 \%)$ \\
Sinks, Mt/yr & $911.5 \pm 134.0(100 \%)$ & $503.5 \pm 22.7(100 \%)$ \\
Turb. dep., Mt/yr & $231.4 \pm 35.8(25 \%)$ & $115.0 \pm 7.8(23 \%)$ \\
Sediment., Mt/yr & $286.5 \pm 41.1(31 \%)$ & $163.6 \pm 8.8(32 \%)$ \\
Wet dep. conv., Mt/yr & $128.7 \pm 19.3(14 \%)$ & $73.6 \pm 5.3(15 \%)$ \\
Wet dep. strat., Mt/yr & $264.3 \pm 43.4(29 \%)$ & $150.0 \pm 3.3(30 \%)$ \\
Load, Mt & $21.5 \pm 2.9$ & $15.1 \pm 1.2$ \\
Lifetime, d & 8.6 & 10.93 \\
\hline
\end{tabular}

are by approximately a factor of 2 larger than in NUDGE. As we initially consider only particles with a mass median diameter of $2.5 \mu \mathrm{m}$ at the source the simulated average global dust emission in our model is in both experiments relatively small compared to other models which cover a broader size range [e.g., Ginoux et al., 2001; Zender et al., 2003]. In additon we underestimate dust from the Southern Hemisphere and from the Asian souces (TS04a). Simulated estimates of the global dust emission lie in the range from 430 to $3000 \mathrm{Mt} / \mathrm{yr}$, but these data are poorly constrained; for a detailed discussion, see Tegen et al. [2002]. It is therefore difficult to assess from the global mass budget which simulation is more realistic. A detailed comparison of CLIM and NUDGE with different observations will address this question in the following sections. The origin of the large difference in emission flux is the $10 \mathrm{~m}$ wind distribution. Please note that we refer to the distribution of the grid cell mean winds and not to a probability function representing the subgrid-scale variability of the wind. The regional pattern of the source parameters threshold velocity, source strength factor and clay content are equal in both models. The $10 \mathrm{~m}$ wind speed and resultant dust emission flux was therefore extracted from the model runs (climatological and nudged) at every time step (24 $\mathrm{min}$ ) in all desert regions. To obtain the frequency distribution of the wind speed and the corresponding dust resuspension fluxes, the analysis is limited to those areas where $99 \%$ of the total dust flux is occurring. Figure 1 shows that a very small difference in the shape of the high-wind tail of the wind speed distribution is responsible for two times larger emissions in CLIM than in NUDGE. It points to the importance of the high wind tail for calculating dust fluxes in a GCM in an interactive manner. The result draws attention to an important source of error for dust simulations also discussed by other authors. Lunt and Valdes [2002] have shown in a suite of sensitivity studies that their model is highly sensitive to a wide range of ill-constrained parameters such as the threshold friction velocity. Tegen et al. [2002] have discussed the importance of gusts mentioning that 6 hourly ECMWF winds underestimate maximum wind speeds occurring, e.g., when squall lines pass by. Werner et al. [2002] found that 12 hourly averaged ECHAM4 winds at T30 resolution produced two times smaller emissions than ECMWF winds at 0.5 degree resolution.

[11] Our study shows another aspect of the problem: The effect of a small difference in wind distribution of the mean winds on dust emissions. For both NUDGE and CLIM we have used the actual simulated surface wind speeds at every time step and at T42 resolution. The fact that NUDGE is relaxed to interpolated ECMWF winds every 24 min seems
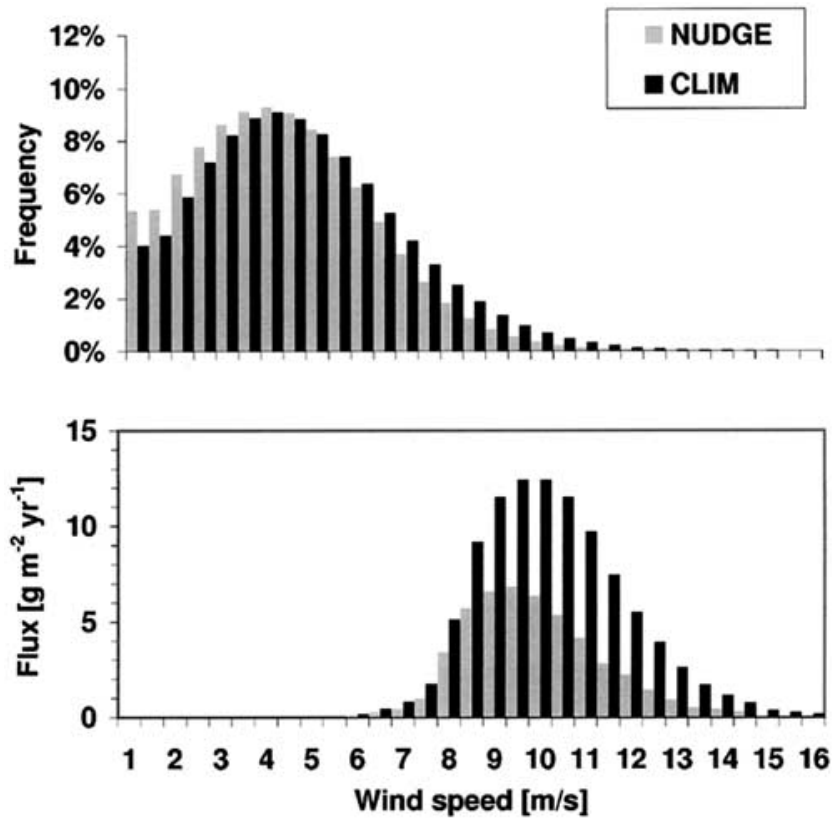

Figure 1. Frequency distribution of grid cell mean winds (top panel) and corresponding distribution of the global dust flux as a function of wind speed (bottom panel). Note that the dust flux distribution is not shown as fraction per wind class, but as total flux per wind class. Statistics are computed from every time step for wind classes with bins defined as $0-1 ; 1-1.5 ; 1.5-2 ; 2-2.5 \ldots \mathrm{m} / \mathrm{s}$. Wind distribution and dust flux distribution are obtained from those desert areas which represent $99 \%$ of the total dust flux. NUDGE represents the years 1986-1991 and CLIM 10 years of simulation.

to damp especially the high winds in the dust source regions. In the CLIM experiment the winds are calculated every $24 \mathrm{~min}$ as a function of evolving meteorology and have therefore a higher variability. With respect to the question of equivalence of both modes of operation of ECHAM we have to conclude that slightly different meteorological boundary conditions are translated to quite substantially different dust emissions. This difference propagates into other properties of the simulated dust fields, which we detail below.

[12] Table 1 reveals that the differences in the dust load are smaller than in the emission fluxes. The dust load in NUDGE is $70 \%$ of CLIM, while the total emission in NUDGE is $55 \%$ of CLIM. The lifetime of dust is almost 11 days in NUDGE while it is only 8.6 days in CLIM. This is a significant difference with important consequences, e.g., for the radiative impact of dust. If we had prescribed the same dust emission flux in both experiments (e.g., equal to

Table 2. Influence of SST

\begin{tabular}{lllll}
\hline & CLIM & NUDGE & SST 86 & SST 89 \\
\hline Source, Mt/yr & 913.1 & 504.2 & 901 & 1040.33 \\
Sinks, Mt/yr & 911.5 & 503.5 & 902 & 1037.83 \\
Mass, Mt & 21.55 & 5.08 & 21.78 & 22.5 \\
Lifetime, d & 8.6 & 10.93 & 8.8 & 7.9 \\
\hline
\end{tabular}


CLIM

DJF

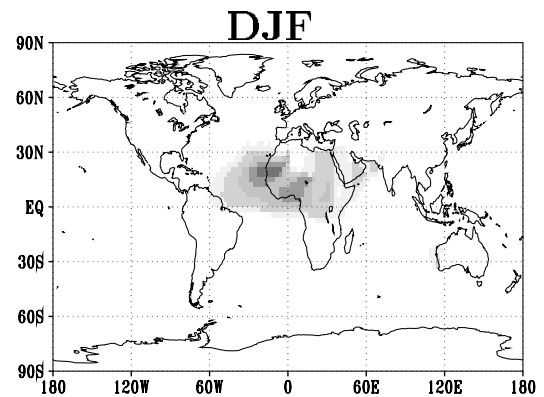

$\begin{array}{lllllll}0.05 & 0.1 & 0.25 & 0.5 & 1 & 2.5 & 5\end{array}$

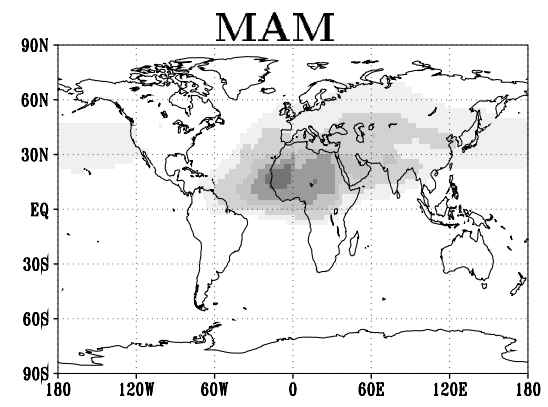

$\begin{array}{lllllll}0.05 & 0.1 & 0.25 & 0.5 & 1 & 2.5 & 5\end{array}$

JJA

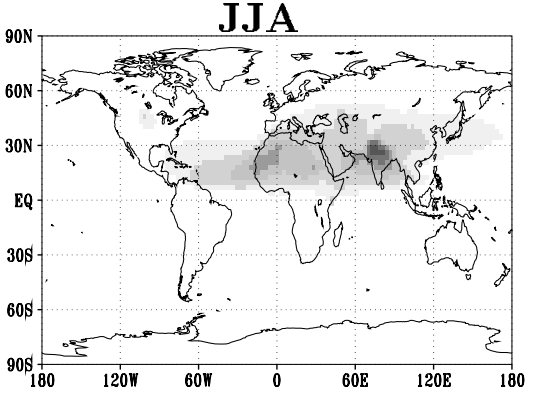

$\begin{array}{lllllll}0.05 & 0.1 & 0.25 & 0.5 & 1 & 2.5 & 5\end{array}$

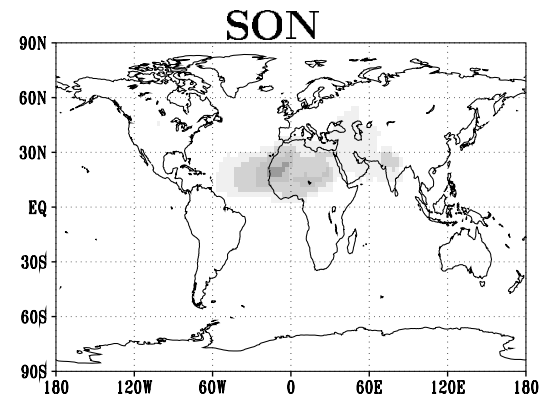

$\begin{array}{lllllll}0.05 & 0.1 & 0.25 & 0.5 & 1 & 2.5 & 5\end{array}$
NUDGE

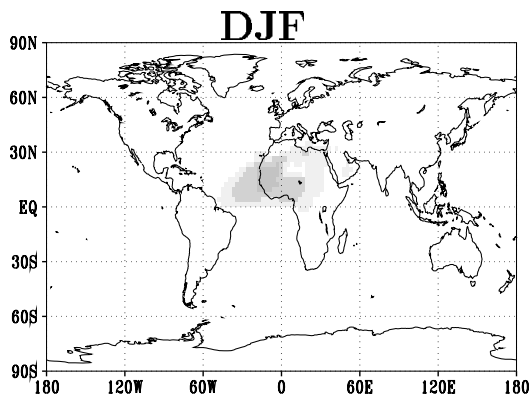

$\begin{array}{lllllll}0.05 & 0.1 & 0.25 & 0.5 & 1 & 2.5 & 5\end{array}$

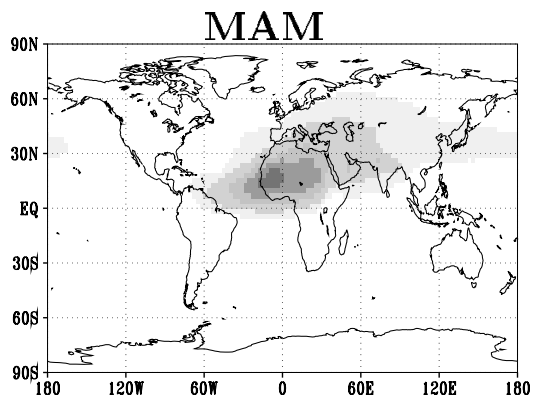

$\begin{array}{lllllll}0.05 & 0.1 & 0.25 & 0.5 & 1 & 2.5 & 5\end{array}$

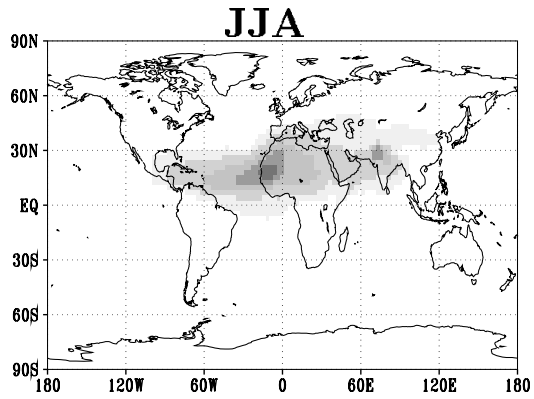

$\begin{array}{lllllll}0.05 & 0.1 & 0.25 & 0.5 & 1 & 2.5 & 5\end{array}$

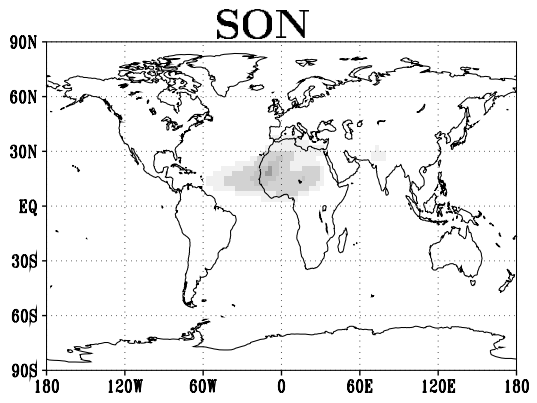

$\begin{array}{lllllll}0.05 & 0.1 & 0.25 & 0.5 & 1 & 2.5 & 5\end{array}$
CLIM- NUDGE
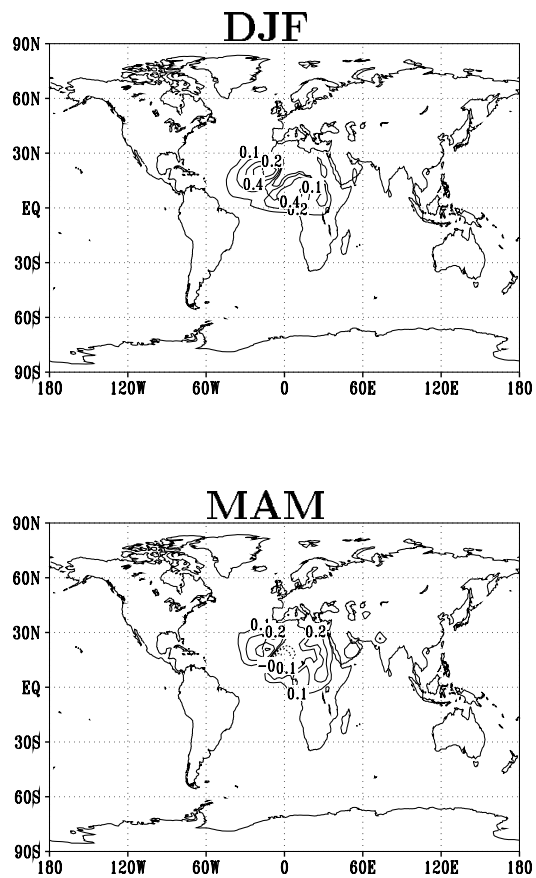

Figure 2. Seasonal distribution of column burden $\left(\mathrm{g} \mathrm{m}^{-2}\right)$ for the CLIM and the NUDGE experiment and their absolute difference.

NUDGE), the dust load would have been $20 \%$ lower in CLIM. One reason for this difference in lifetime may be due to a different repartitioning among the four sink processes (turbulent dry deposition, sedimentation, convective and stratiform wet deposition). However, in both experiments the distribution among the sinks is almost equal and thus can not right away explain the difference in lifetime. Another explanation for the reduced lifetime in CLIM might be that source regions in CLIM are nearer to efficient sinks. We will discuss this point in more detail in section 3.3.

[13] In the nudged mode we have nudged meterological fields (vorticity, divergence, temperature and surface pres- 

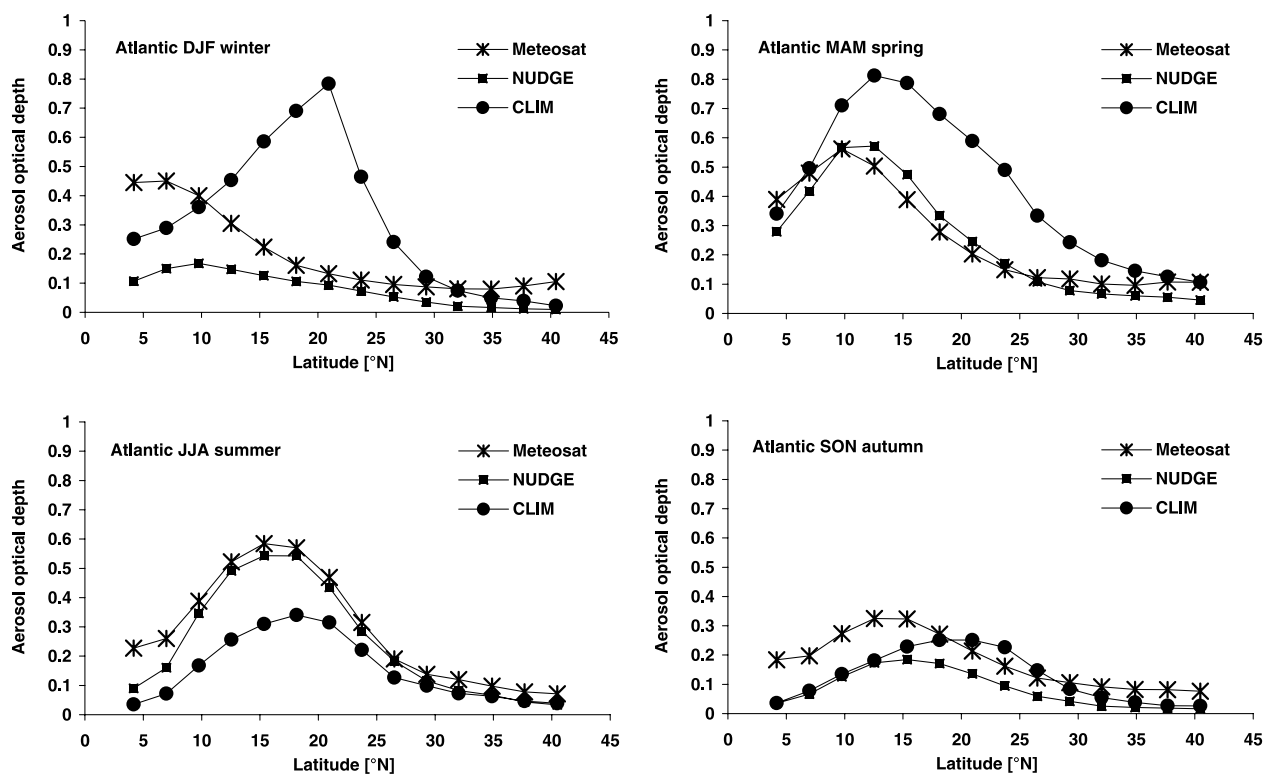

Figure 3. Longitudinal averaged optical depth $(\lambda=0.55)$ over the Atlantic, but for marine cloud-free area. Shown are both experiments and satellite observations. Averaged are years 1-10 (CLIM) and 1986-1991 (NUDGE).

sure) and prescribed daily observed SSTs based on ECMWF data. To test how important a daily varying SST is for the dust, we have performed two ensemble calculations in the climatological mode. SST fields have been chosen for the particular years 1986 and 1989. 1986 was a year with a relative low dust load and 1989 a year with a relative high dust burden. For each ensemble 6 ensemble members have been computed. Each member comprises a one year simulation with different initial fields. The influence of daily prescribed SSTs on the aerosol concentration is relatively small. Table 2 indicates that the major difference in the global overall mass budget results from nudging the model to observed meteorological fields. The differences between NUDGE and the CLIM are much more pronounced than the differences between CLIM and the SSTs experiment. The emission flux in the SST89 experiment is higher and in the SST86 lower than in CLIM in good agreement to observations. The differences are, however, small and within one standard deviation of the CLIM experiment (Table 1).

\subsection{Geographical Distribution of Mineral Dust}

[14] Figure 2 shows the mineral dust distribution for the four seasons. The general features of dust distribution in both model experiments are similar. In both experiments the maximum dust burden is found in Northern Hemisphere (NH) spring and summer. The position of the Sahran dust plume is shifted more south in $\mathrm{NH}$ winter and more north during NH summer. As discussed in TS04A the model version we have used underestimates dust from Asia and the Southern Hemisphere. The differences between NUDGE and CLIM depend strongly on region and season. CLIM is usually more spread especially to the north and stronger in western Africa, especially during fall and winter, except for the summer season. In NH summer the maximum over Asia is in CLIM one magnitude higher than in NUDGE, while the Saharan dust plume is higher in the NUDGE simulation.
[15] It would be nice to show that the position and strength of the Saharan dust plume is more realistic in either the NUDGE or the CLIM experiment. To illustrate this, we have averaged the model data, and for comparison Meteosat satellite data [Moulin et al., 1997] of aerosol optical depth at $\lambda=0.55 \mu \mathrm{m}$ in the area between $0^{\circ}$ and $40^{\circ} \mathrm{N}$ and up to ca. $40^{\circ} \mathrm{W}$ in the marine cloud-free areas for each season (Figure 3). To have comparable satellite observations and model results, we averaged the simulated daily noon values over marine cloud free areas. The latter areas are identified from the satellite product. Meteosat satellite data were averaged for the years 1986-1991 corresponding to the NUDGE time period. This comparison follows a strategy applied already in Schulz et al. [1998].

[16] Since Meteosat detects also other aerosol components, the comparison between our model and aerosol optical depth is straightforward where dust is the dominant aerosol component, i.e., over the tropical and subtropical North Atlantic. In the south, biomass burning aerosol contribute to about $50 \%$ of the total optical depth during the burning season [Tegen et al., 1997]. In the northern latitudes, pollution plumes can reach the Atlantic from Europe [e.g., McGovern et al., 1999; Garrett et al., 2003]. In consequence the model should rather underestimate aerosol optical depth which it does.

[17] NUDGE agrees in general much better with the Meteosat data in the region of high dust load between $10^{\circ} \mathrm{N}$ and $30^{\circ} \mathrm{N}$. In CLIM the area of maximum optical depth is further north compared to NUDGE and Meteosat in all seasons. The largest shift of $\left(10^{\circ}\right)$ is found in $\mathrm{NH}$ winter. Owing to the northerly shift of the plume and higher emission, CLIM overestimates the aerosol optical depth in a band between $10^{\circ} \mathrm{N}$ and $30^{\circ} \mathrm{N}$. This indicates that the CLIM mode of ECHAM has a significantly altered circulation in the subtropical Atlantic and northern African region. The latitudinal shift of the Saharan dust plume in 
DJF

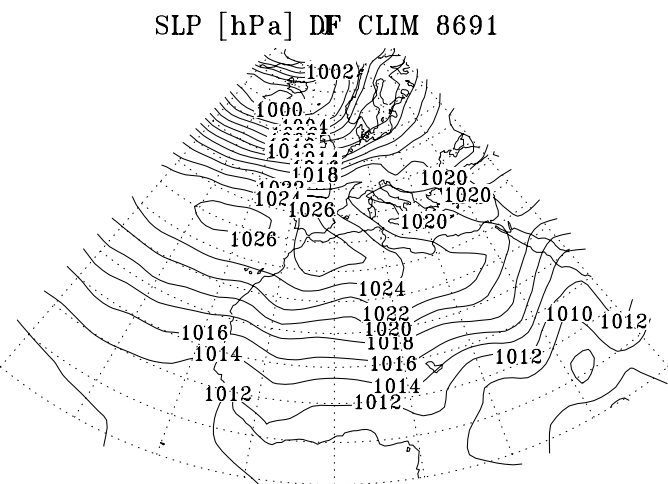

SLP $[\mathrm{hPa}]$ DF NUD 8691

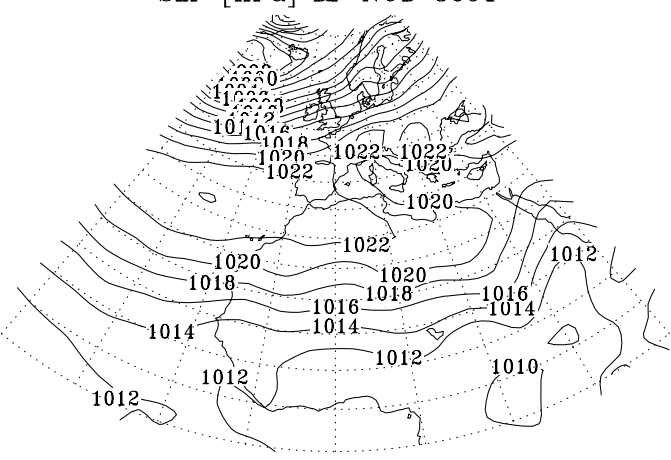

SLP $[\mathrm{hPa}]$ DF CLIM- NUD

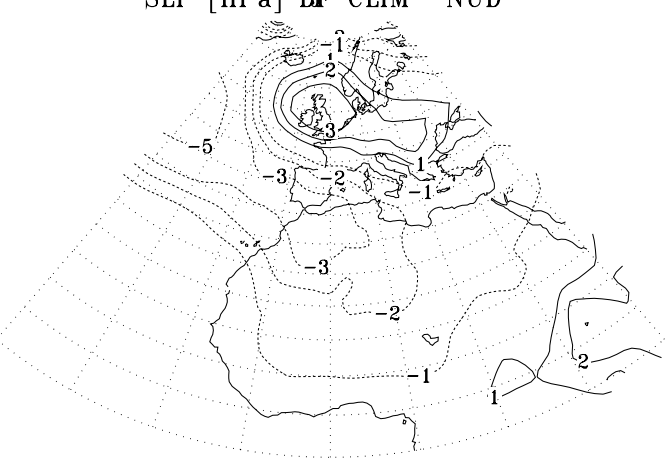

JJA

SLP $[\mathrm{hPa}]$ IA CLIM 8691

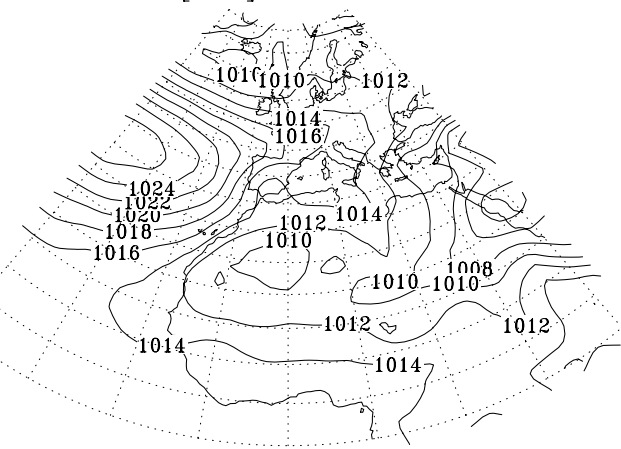

SLP [hPa] JA NUD 8691

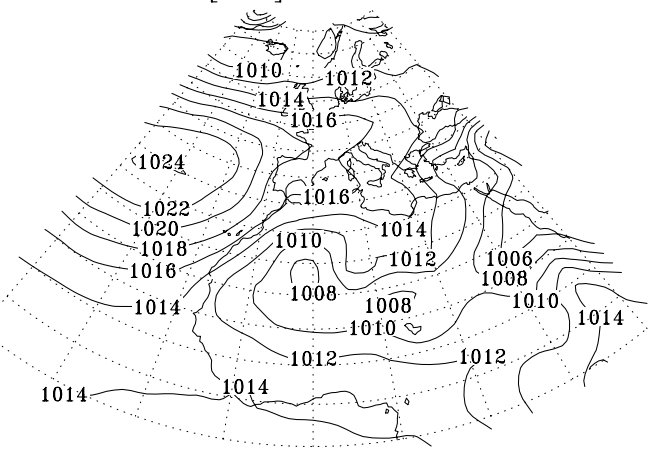

SLP [hPa] JA CLIM - NUD

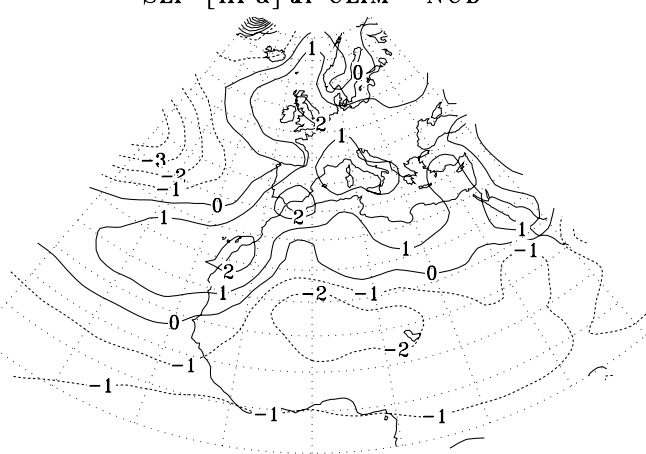

Figure 4. Sea level pressure $(\mathrm{hPa})$ in the NUDGE and CLIM experiment and the difference between both experiments for $\mathrm{NH}$ summer and winter.

CLIM has important consequences for the aerosol radiative feedback in particular in $\mathrm{NH}$ winter. The maximum of the dust plume during $\mathrm{NH}$ winter is shifted near $21^{\circ} \mathrm{N}$. The total cloud cover over the North Atlantic has a local minimum at these latitudes. Thus in CLIM the local dust plume exerts a strong reduction to the solar surface fluxes.

[18] The better agreement of NUDGE with Meteosat can be explained with a more realistic position and strength of the Azores high. The Azores high is important for the dust transport from Africa in the trade wind layers [Chiapello et al., 1995]. Roeckner et al. [1996] found that in ECHAM4 in the climatological mode the Azores high is too strong and extended too far eastward over the Mediterranean in $\mathrm{NH}$ winter. The sea level pressure (SLP) in the NUDGE and in the CLIM experiment and their difference is shown in Figure 4 for the winter and summer season. The Azores high is stronger in the CLIM experiment in both seasons in particular in $\mathrm{NH}$ winter where it is shifted far more eastward compared to the NUDGE experiment.

\subsection{Annual Cycle}

[19] The annual cycle provides further insight of the globally averaged emission flux, dust load and lifetime for NUDGE and CLIM (Figure 5). Note, that the dust load in 
a)

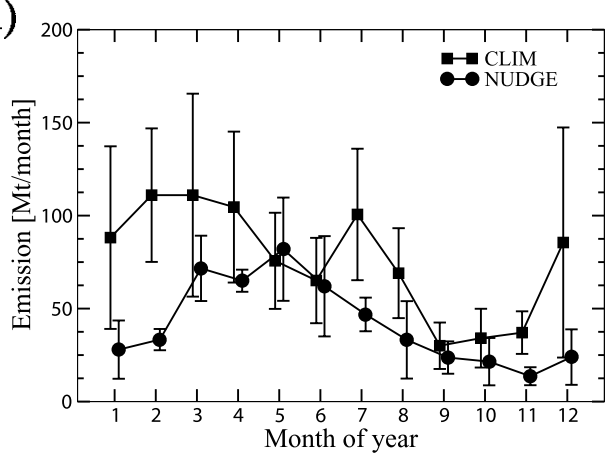

b)

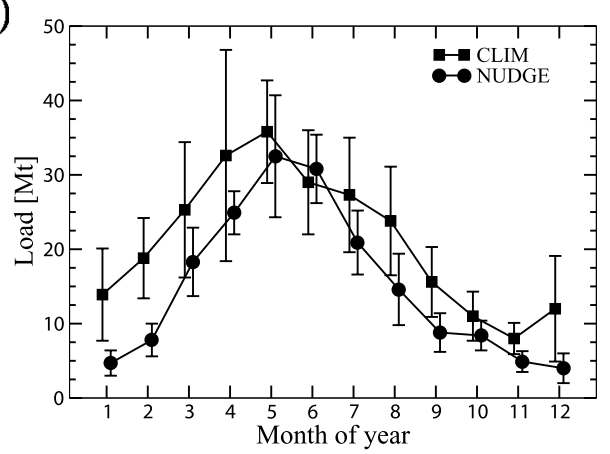

c)

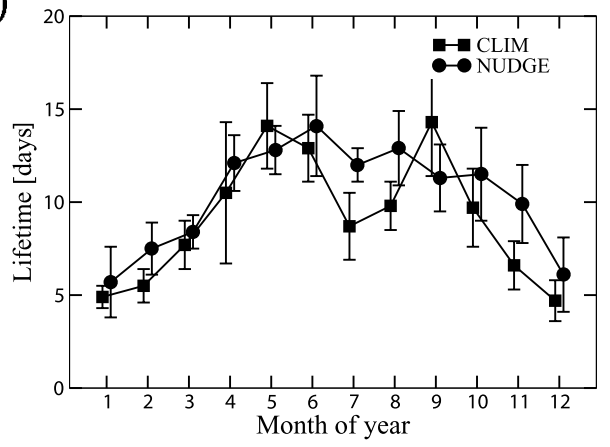

Figure 5. Average annual cycle of (a) emission (Mt/ month), (b) total dust load (Mt), and (c) atmospheric lifetime (days). The bars indicate the standard deviation from 6 (NUDGE) resp. 10 (CLIM) years.

CLIM is on the average higher, because of the higher emissions in CLIM. Figure 5a shows that the annual cycle of the emission is significantly different between both experiments. Largest differences in the dust emission occur in winter. This results mainly from the overestimation and mislocation of the Azores high in the CLIM experiment (Figure 4) leading to high dust values over the subtropical northeast Atlantic (Figures 2 and 3). The summer months are characterized by long-range transport over the North Atlantic. High dust loads in CLIM extend into August because strong dust emission are simulated over the Thar desert in CLIM despite reduced emissions of North Africa.

[20] For NUDGE the maximum of mean dust load in May is well correlated with the maximum of dust emission, while it is not the case for the CLIM experiment. Figure 5b shows that in the CLIM experiment the highest dust load occurs in
April and May in contrast to the emission maxima in February/March and July. The reason for this different behavior can be found in the average annual cycle of atmospheric lifetime, calculated as the ratio of monthly average load and corresponding absolute values of total sinks in that month (Figure 5c). The annual cycle of lifetime shows for the CLIM experiment a distinct local minimum in July and August. As a consequence, the summer emission maximum does not appear in the annual cycle of mean dust load.

[21] An explanation of this distinct local minimum in July and August in CLIM might be found in the sink processes. Although the annual mean of the relative contribution of the different sink processes do not differ between both experiments (Table 1) smaller differences between them are found on the monthly basis (not shown). In NH summer the contribution of the wet deposition processes is larger in CLIM while the contribution of the dry deposition processes is larger in NUDGE. This can be explained with the comparable large amount of Thar desert dust aerosol in CLIM, which is mainly removed by wet deposition. Differences between CLIM and NUDGE occur in NH winter particular for the dry deposition processes. The contribution of sedimentation is larger in NUDGE while in CLIM the contribution of the turbulent deposition processes is stronger.

[22] A further explanation might be found in the geographical distribution. Figure 6 depicts the ratio between column burden and total sinks (local lifetime) in the NUDGE and in the CLIM experiment in winter and summer. In $\mathrm{NH}$ winter the local lifetime over the North Atlantic is in general in the order of 2-4 days in CLIM and slightly higher in NUDGE (4-6 days). Higher values $>6$ days are only found over the Gulf of Guinea and the Sahel region. In NH summer the local atmospheric lifetime over the North Atlantic is about a factor of 5 larger than in NH winter. These strong seasonal differences over the North Atlantic are related to the different vertical aerosol distribution in summer and in winter and will be further discussed in the next section. Low values $<6$ days are found in the ITCZ and over the Indian subcontinent where the particles are removed by wet deposition. Over the Indian subcontinent the lifetime is comparable low in the CLIM experiment compared to NUDGE which can together with the strong source over the Thar desert in CLIM explain the distinct local minimum in the CLIM experiment in Figure 5c.

\subsection{Vertical Distribution}

[23] Meridional cross sections of the zonally averaged dust concentrations are shown for the CLIM and the NUDGE experiment in Figure 7 for winter and summer season. The vertical dust distribution varies seasonally with more dust at higher altitudes in $\mathrm{NH}$ summer. In $\mathrm{NH}$ winter the simulated dust concentration decreases in both experiments rapidly with height while in $\mathrm{NH}$ summer values of $10 \mu \mathrm{gm}^{-3}$ are still found in the free troposphere. Differences between NUDGE and CLIM partially reflect the different emissions (Table 1). The simulated dust concentrations are in $\mathrm{NH}$ in general much higher in CLIM and the second maximum around $30^{\circ} \mathrm{S}$ from the Australian sources occur only in the CLIM model run. In NH summer more dust is 
CLIM

D.JF

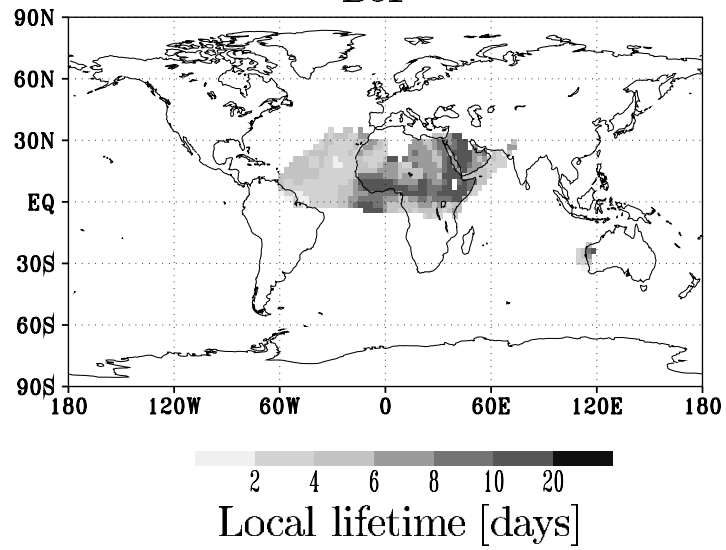

JJA

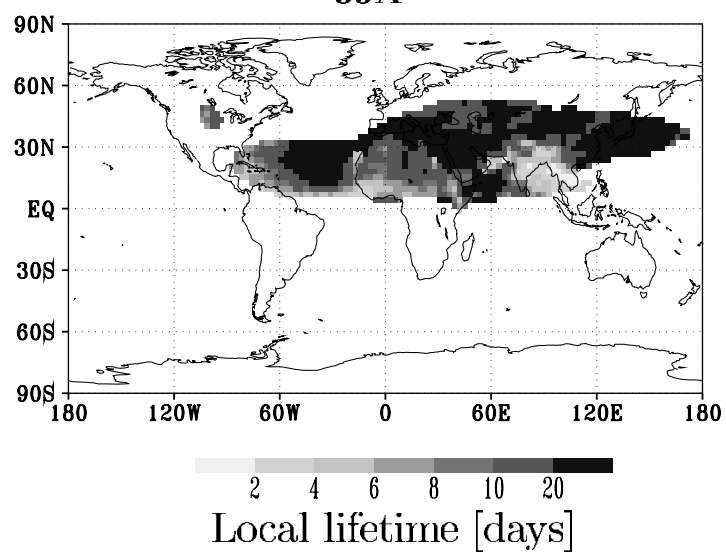

NUDGE

DJF

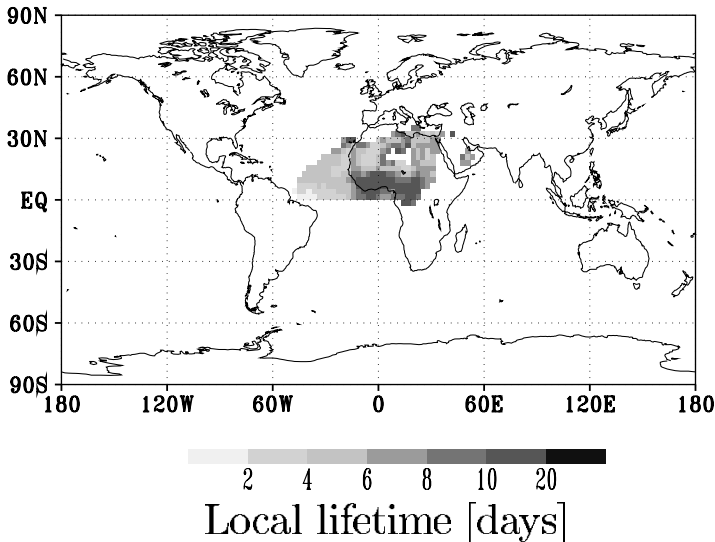

J.JA

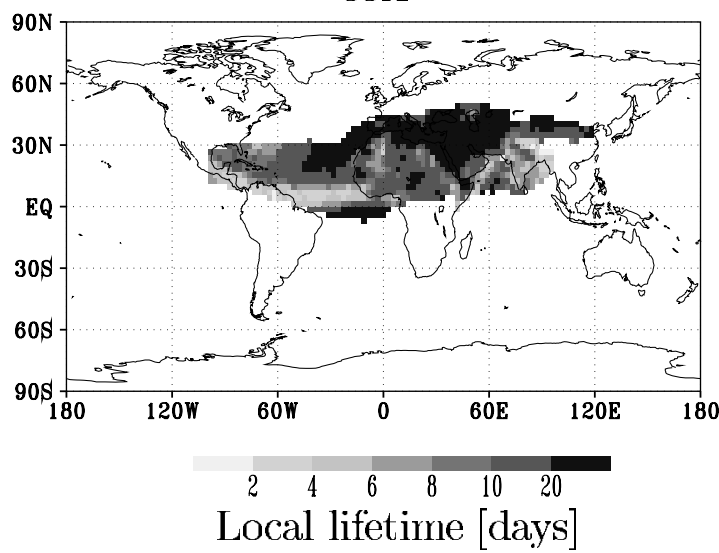

Figure 6. Local lifetime (load/sinks) (days) in NUDGE and CLIM for winter and summer. Only those regions are shown where the dust column burden is larger than $0.05 \mathrm{~g} \mathrm{~m}^{-2}$.

found in CLIM in the latitudes north of $20^{\circ} \mathrm{N}$, reflecting the strong Thar desert source while the higher dust concentrations in NUDGE between $0^{\circ} \mathrm{N}$ and $20^{\circ} \mathrm{N}$ result from the Saharan dust plume. In contrast to the NUDGE experiment meridional northward transport occurs in CLIM in $\mathrm{NH}$ winter between 900-800 hPa. Poleward transport to the northern high latitudes is found in $\mathrm{NH}$ summer in both experiments between 500 and $800 \mathrm{hPa}$.

[24] A quantity which can be more easily compared between the experiments than the meridional cross section is the mean altitude. Figure 8 shows the geographical distribution of the mean altitude of mineral dust (expressed as sum over the product of seasonal dust concentration and height, divided by the vertical integral of dust concentration) for both experiments. The mean altitude increases with distance from the source region because the particles are removed at lower altitudes due to sedimentation. The mean altitude of dust concentration differs from summer to winter, which has implication for the long-range dust transport of Saharan dust across the Atlantic. During NH summer more convection takes place lifting mineral dust up to relative high altitudes. Dust transport takes place above the marine boundary layer in the so called Saharan Air layer (S.A.L.). Observations [Carlson and Prospero, 1972; Prospero and Carlson, 1972] show that the S.A.L. often reaches altitudes of $5-7 \mathrm{~km}$ and extends across the Atlantic to the Caribic and southeast Coast of the United States. In NH winter the differences in the mean altitude of the Saharan dust plume over the North Atlantic are small between both experiments and largely influenced by the mislocation of the Azores high as discussed in section 3.2. In NH summer the mean altitude of the mineral dust in the North Atlantic dust plume is about $3 \mathrm{~km}$ and $0.5-1 \mathrm{~km}$ lower in NUDGE compared to CLIM which is consistent with the smaller local lifetime in NUDGE in that region, see Figure 6. At the edges of the NH summer dust plume the mean altitude increases. Convective activity leads to an increase in the mean altitude height at the southern edge of the Saharan dust plume. The elevation of the dust particles at the northern edge of the Saharan plume can be explained with the lofting along the isentropes of the midlatitudinal frontal systems [Karyampudi et al., 2002]. Small changes in the latitudinal distribution of the North African dust plume can therefore have a large impact on the vertical distribution and thus also on the mean altitude.

\subsection{Cross-Atlantic Transport}

[25] To investigate the cross-Atlantic transport in both modes we have defined transport factors $\mathrm{Tf}$ as fraction of the averaged mineral dust load between $0^{\circ}$ and $40^{\circ} \mathrm{N}$ at two 

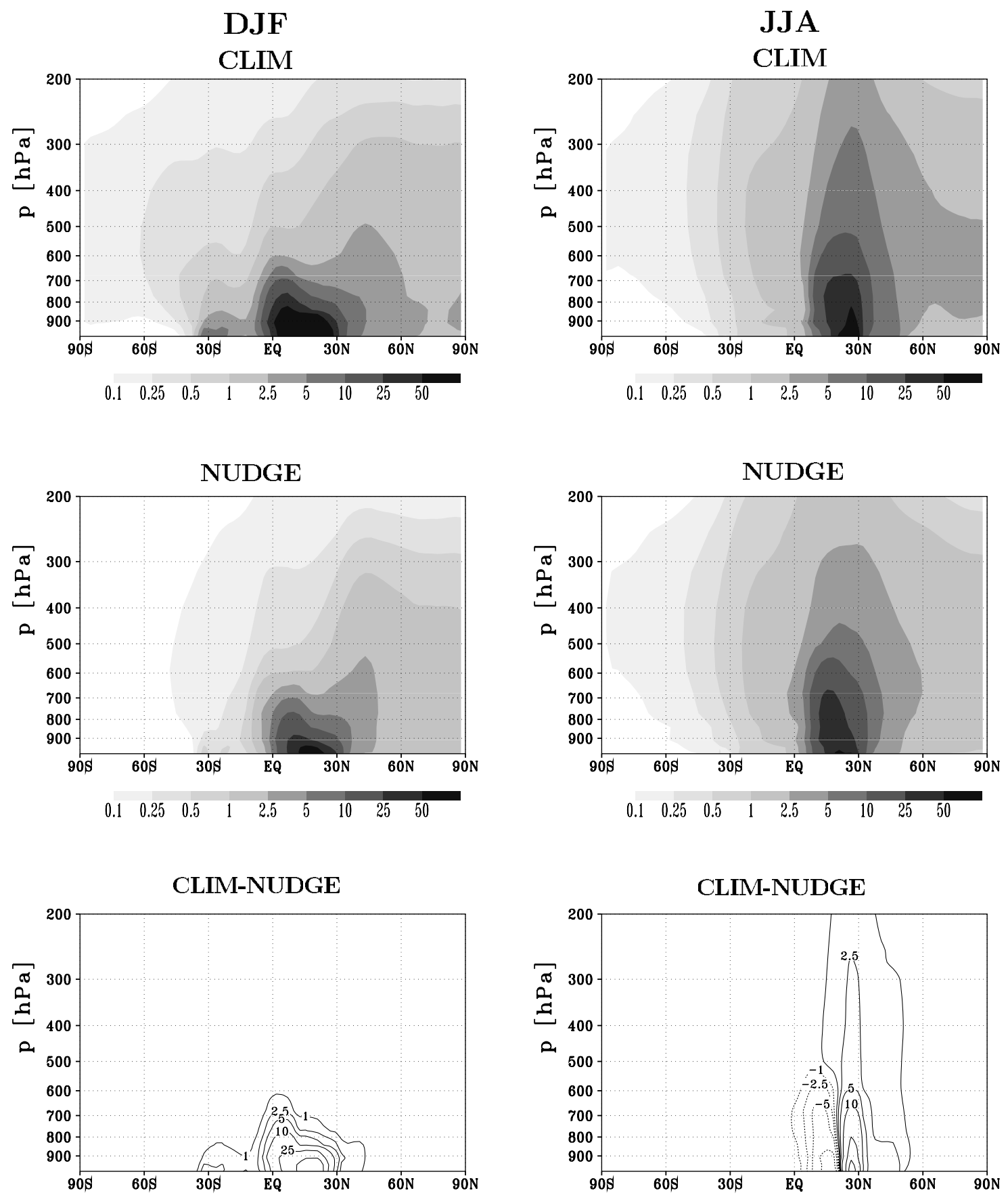

Figure 7. Meridional cross section of the zonally averaged dust concentration in NUDGE and CLIM and the difference between both experiments for DJF and JJA.

different meridians over the North Atlantic $40^{\circ} \mathrm{W}$, and $80^{\circ} \mathrm{W}$ divided by the averaged dust load over the same latitudes at $20^{\circ} \mathrm{W}$ (Table 3). The cross-Atlantic transport is seasonally dependent. While in $\mathrm{NH}$ summer the aerosol load at $80^{\circ} \mathrm{W}$ is between $25-30 \%$ of the aerosol load at $20^{\circ} \mathrm{W}$, the comparable fraction in $\mathrm{NH}$ winter is less than $5 \%$. This indicates that more dust is deposited downwind of the African coast in $\mathrm{NH}$ winter than in summer. The differences in the two Tf values are small between both experiments for the annual average but are quite large for specific seasons. While for NH summer and autumn the mean values of $\mathrm{Tf}$ at $80^{\circ} \mathrm{W}$ are quite close, they differ for winter and spring by more than $30^{\circ}$. These values are the only ones where the mean difference is significant at least at the $95 \%$ confidence interval, see Table 3 . The relative amount of dust transported in winter over the Atlantic to $80^{\circ} \mathrm{W}$ is twice as high in NUDGE compared to CLIM. This can be explained with the shift of the Azores high in CLIM.

[26] An independent measure of the cross-Atlantic transport is the comparison of simulated surface dust concentrations with observations at North Atlantic sites. In Figure 9 the mean simulated seasonal cycle is plotted along with ground-based measurements of dust concentration of the AEROCE network operated by the University of Miami 


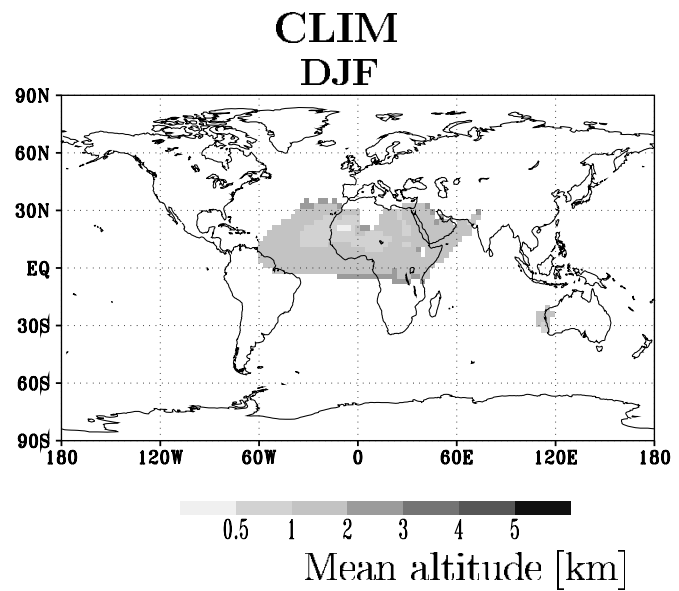

JJA

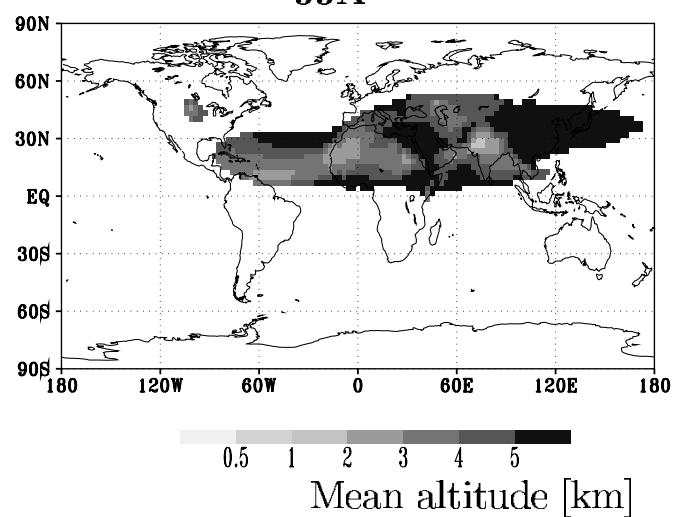

NUDGE

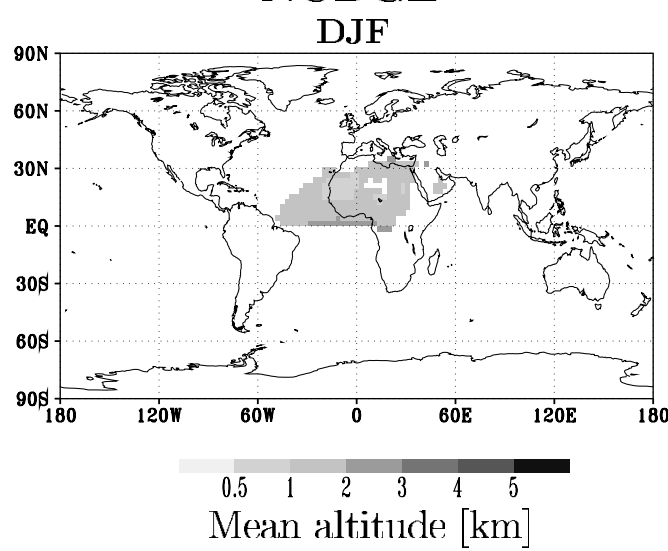

JJA

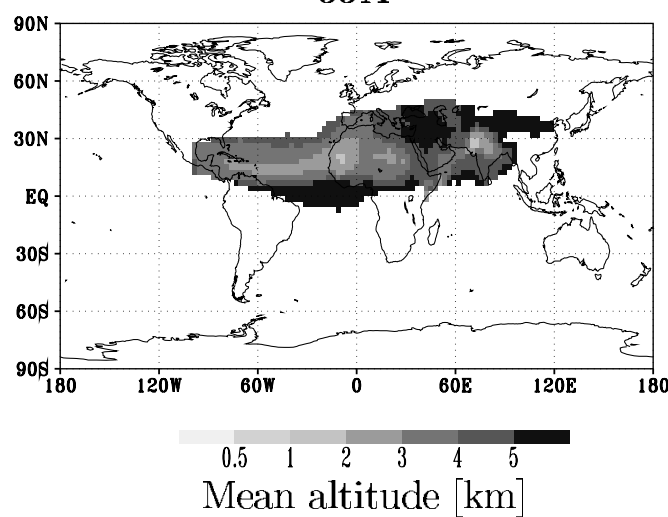

Figure 8. Mean altitude of dust concentration $(\mathrm{km})$ in NUDGE and CLIM for DJF and JJA. Only the regions are shown where the dust concentration is larger than $0.05 \mathrm{~g} \mathrm{~m}^{-2}$.

[Prospero, 1996] during the 1980s and 1990s. Izaña is closest to the African source areas and dust is thus pretty variable in this region. While CLIM and NUDGE both reproduce the early spring maximum, the observed maximum in late summer is found only with NUDGE. CLIM on the other hand overestimates April values at this mountain station. Izaña in summer is located exactly on the northern edge of the distinct summer dust plume (see Figure 2). A small displacement in any particular month of the modeled plume might lead to large discrepancies with reality.

[27] At Barbados the annual cycle reflects the annual emission cycle in northern Africa. As shown in Table 3, transport efficiency up to $40^{\circ} \mathrm{W}$ is similar in CLIM and NUDGE, and doubles from winter to summer. Large concentrations in midwinter and a strong and too early dust plume in April and May in CLIM precede the time of the observed annual dust maximum at Barbados (June). It confirms our hypothesis (see also Figure 3), that winter and spring North African emissions in CLIM are too high by a factor of at least factor two. Although the seasonal variation in NUDGE seems to be correct, summer NUDGE values suggest that dust emissions are overestimated in summer (TS04A).

[28] Miami is situated at the far end of the Saharan dust plume. Significant dust loads arrive only in summer at these locations. Transport efficiency (see Table 3 ) toward $80^{\circ} \mathrm{W}$ is a factor five larger in summer than in winter. Seasonal cycles differ only slightly between CLIM, NUDGE and observations. The principal differences discussed above for Barbados reappear, but are slightly less important. However, simulated summer concentrations are not larger than those observed, in contrast to what we have described above for Barbados.

\section{Summary and Conclusions}

[29] We have investigated the mean geographical distribution and the seasonal variability of soil dust aerosol with

Table 3. Transport Factors Tf for the Cross-Atlantic Transport of Mineral Dust ${ }^{\mathrm{a}}$

\begin{tabular}{lccccc}
\hline & \multicolumn{2}{c}{ CLIM } & & \multicolumn{2}{c}{ NUDGE } \\
\cline { 2 - 3 } \multicolumn{1}{c}{ Season } & $\mathrm{Tf}_{40 / 20}$ & $\mathrm{Tf}_{80 / 20}$ & & $\mathrm{Tf}_{40 / 20}$ & $\mathrm{Tf}_{80 / 20}$ \\
\hline DJF & $\mathbf{0 . 2 5}$ & $\mathbf{0 . 0 3}$ & $\mathbf{0 . 2 9}$ & $\mathbf{0 . 0 5}$ \\
MAM & 0.35 & 0.11 & 0.35 & 0.08 \\
JJA & 0.59 & 0.26 & 0.63 & 0.25 \\
SON & 0.41 & 0.12 & 0.43 & 0.11 \\
Annual Av. & 0.40 & 0.13 & 0.43 & 0.12 \\
\hline
\end{tabular}

${ }^{\mathrm{a}} \mathrm{Tf}_{X / 20}$ is defined as fraction of the averaged mineral dust load between $0^{\circ}$ and $40^{\circ} \mathrm{N}$ at $40^{\circ} \mathrm{W}$ resp. $80^{\circ} \mathrm{W}$, divided by the averaged dust load over the same latitudes at $20^{\circ} \mathrm{W}$. The bold values indicate transport factors where the mean difference is significant at least at the $95 \%$ confidence interval ( $\mathrm{t}$-test). 

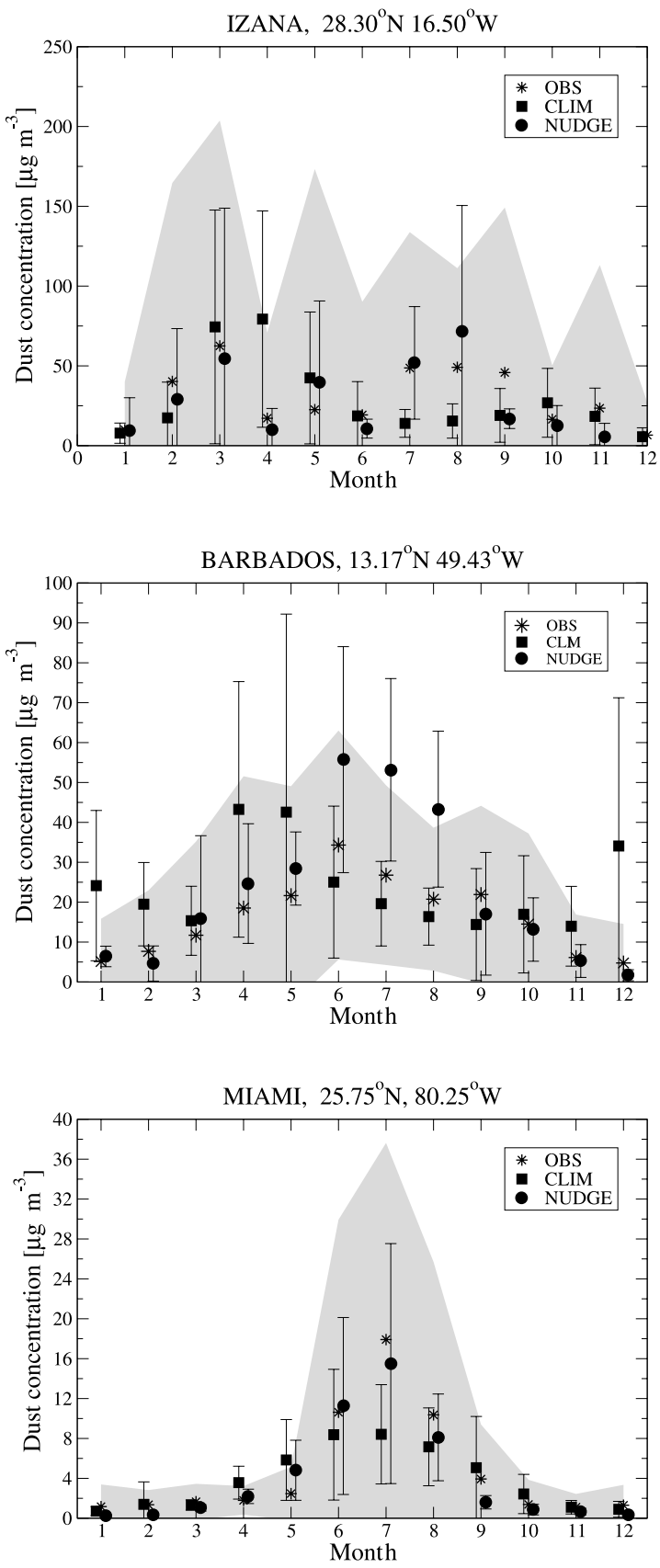

Figure 9. Comparison of simulated monthly mean dust concentrations at the surface with observed dust concentrations [Prospero, 1996] at three different North Atlantic stations. The shaded area envelopes the mean observed dust concentration (stars) \pm one standard deviation. The NUDGE results (circles) are averaged over the period (1986-1991) and the CLIM results (squares) over 10 years. The bars indicate the standard deviation from 6 (NUDGE) resp. 10 (CLIM) years.

the climate model ECHAM4. ECHAM4 has been operated in two modes of operation, a climatological mode with prescribed climatological SST (CLIM) and a nudged mode where the model is forced by ECMWF Reanalysis data of the particular years 1986-1991 (NUDGE). Our simulations show that the global budget, the mean geographical distri- bution and the seasonal variability of mineral dust change as these different modes are applied to the climate model. The differences are seasonally dependent. Largest deviations occur in $\mathrm{NH}$ winter and are related to the overestimation and the mislocation of the Azores high in ECHAM4. This model bias has significant implication for the emission flux, the position of the Sahran dust plume, the cross-Atlantic transport and the time evolution of the aerosol. The atmospheric lifetime is longer in the nudged model run and the maximum of the total dust load is delayed by one to two months compared to the climatological run. CLIM has a tendency to produce more dust due to higher wind speeds, which result in higher global emission. The importance of the high wind tail of the wind speed distribution for the resulting mineral flux is evident. The magnitude seems to depend more on the surface winds and thus also on the boundary layer meteorology implemented in the GCM. As pointed out recently by Grini and Zender [2004], capturing the high wind tail might not be sufficient to represent mineral dust in a realisitc manner. Nonlinear interactions between subgrid-scale wind distribution, soil size distribution and the dust production processes have an important effect on the resultant long-range-transported dust mass and size distribution.

[30] The influence of daily prescribed SSTs on the aerosol concentration is relatively small. The major difference in the global overall mass budget results from nudging the model to the observed meteorology. It appears that the mode of operation of the climate model seems to be as important as the simulated interannual variability. Small differences in the circulation pattern between both operation modes could have large consequences for source activation and dust transport. This has to be taken into account when climate change experiments are performed.

[31] Differences between NUDGE and CLIM might therefore not only be relevant for mineral dust aerosol but also for other aerosol components with wind driven emission fluxes e.g sea salt. Sea salt simulations with ECHAM4 show that differences in the global budget between both experiments are within 20\% [Timmreck and Schulz, 2003] and therefore smaller than for mineral dust. The differences between both experiments could be explained with the fact that in contrast to sea salt mineral dust sources are more localized partially restricted to one or two model grid points. The source activation is therefore more critical for mineral dust. However, significant differences occur in the interannual variability of sea-salt aerosol between NUDGE and CLIM (C. Timmreck et al., manuscript in preparation, 2004). We therefore propose that climate model simulation of aerosol and other trace components, which are strongly wind dependent, should be validated in all modes of operation in order to understand and to reduce model related uncertainties.

[32] Acknowledgments. This work has been supported by the German/French PROCOPE programme (D/0122927) and by the German Aerosol Research program under grant $07 \mathrm{AF} 312 \mathrm{~B} / 7$. Stefan Kinne and Hans Feichter gave valuable comments on an earlier version of this paper. We are greatly indebted to Model and Data Group, Hamburg, for providing the reanalysis data ERA15 (ECMWF/DWD/DKRZ: 1996), to J. Prospero and D. Savoie for the dust concentration from the AEROCE program, to T. Claquin and Y. Balkanski for the dust source and to C. Moulin for the Meteosat satellite observations. Computations were done with the help of 
the DKRZ and the MPI-für Meteorologie, Hamburg. This is LCSE contribution 1155 .

\section{References}

Balkanski, Y., M. Schulz, T. Claquin, C. Moulin, and P. Ginoux (2003), Global emissions of mineral aerosol: Formulation and validation using satellite imagery, in Emission of Atmospheric Trace Compounds, edited by C. Granier, P. Artaxo, and C. E. Reeves, pp. 253-282, Kluwer Acad., Norwell, Mass.

Carlson, T. N., and J. M. Prospero (1972), The large-scale movement of Saharan air outbreaks over the northern equatorial Atlantic, J. Appl. Meteorol., 11, 283-297.

Chadwick, L. A., O. A. Derry, P. M. Vitousek, B. Huebert, and L. O. Hedin (1999), Changing sources of nutrients during four million years of ecosystem development, Nature, 397, 491-497.

Chiapello, I., G. Bergametti, L. Gomes, B. Chatenet, F. Dulac, J. Pimenta, and E. Santos Suares (1995), An additional low layer transport of Sahelian and Saharan dust over the northeastern tropical Atlantic, Geophys. Res. Lett., 22, 3191-3194.

Claquin, M. T. (1999), Modelisation de la minéralogie et du forçage radiaitf des possières désertiques, Ph.D. thesis, Univ. Paris VI, Paris, France.

Claquin, T., M. Schulz, Y. Balkanski, and O. Boucher (1998), Uncertainties in assessing the radiative forcing by mineral dust, Tellus, Ser. B, 50, $491-$ 505.

Dentener, F. J., G. R. Carmichael, Y. Zhang, J. Lelieveld, and P. Crutzen (1996), The role of mineral aerosol as a reactive surface in the global tropsphere, J. Geophys. Res., 101, 22,869-22,889.

Garrett, T. L., L. M. Russell, V. Ramaswamy, S. F. Maria, and B. J. Huebert (2003), Microphysical and radiaitve evolution of aerosol plumes over the tropical North Atlantic Ocean, J. Geophys. Res., 108(D1), 4022, doi:10.1029/2002JD002228.

Gates, W. L., et al. (1998), An overview of the results of the Atmospheric Model Intercomparison Project (AMIP I), Bull. Am. Meteorol. Soc., 73, $1962-1970$.

Ginoux, P., M. Chian, I. Tegen, J. M. Prospero, B. Holben, O. Dubovik, and S. J. Lin (2001), Sources and distributions of dust aerosols simulated with the GOCART model, J. Geophys. Res., 106, 20,255-20,273.

Grini, A., and C. S. Zender (2004), Roles of saltation, sandblasting, and wind speed varaibilty on mineral dust aerosol size distribution during the Puerto Rican Dust Experiment (PRIDE), J. Geophys. Res., 109, D07202, doi:10.1029/2003 JD004233.

Hoke, J. E., and A. Anthes (1976), The initialization of numerical models by a dynamic-initialization technique, Mon. Weather Rev., 104, 15511556

Jeuken, A. B. M., P. C. Siegmund, L. Heijboer, J. Feichter, and L. Bengtsson (1996), On the potential of assimilating meteorologica analyses into a global climate model for the purpose of model validation, J. Geophys. Res., 101, 16,939-16,950.

Karyampudi, V. M., et al. (2002), Validation of the Saharan Dust Plume Cionceptual Model using lidar, Meteosat, and ECMWF data, Bull. Am. Meteorol. Soc., 12, 81-114.

Korhonen, H., I. Napari, C. Timmreck, H. Vehkamäki, L. Pirjola, K. E. J. Lehtinen, A. Lauri, and M. Kulmala (2003), Heterogeneous nucleation as a potential sulphate-coating mechanism of atmospheric mineral dust particles and implications of coated dust on new particle formation, J. Geophys. Res., 108(D17), 4546, doi:10.1029/2003JD003553.

Krishnamurti, T. N., J. Xue, H. S. Bedi, K. Ingles, and D. Oosterhof (1991), Physical initialization for numerical weather prediction over the tropics, Tellus, Ser. AB, 43, 53-81.

Lohmann, U., and E. Roeckner (1996), Design and performance of a new cloud microphysics scheme developed for the ECHAM general circulation model, Clim. Dyn., 12, 557-572.

Lunt, D. J., and P. J. Valdes (2002), The modern dust cycle: Comparison of model results with observations and study of sensitivities, J. Geophys Res., 107(D23), 4669, doi:10.1029/2002JD002316.

Luo, C., N. Mahowald, and J. del Corral (2003), Sensitivity study of meteorological parameters on mineral aerosol mobilization, transport, and distribution, J. Geophys. Res., 108(D15), 4447, doi:10.1029/ 2003JD003483.

Marticorena, B., and G. Bergametti (1995), Modeling the atmospheric dust cycle: 1. Design of a soil-derived dust emission scheme, J. Geophys. Res., $100,16,415-16,430$
Martin, J. A. (1991), Iron still comes from above, Nature, 353, 123

McGovern, F. M., F. Raes, and R. Van Dingenen (1999), Anthropogenic influences on the chemical and physical properties of aerosols in the Atlantic subtropical region during July 1994 and July 1995, J. Geophys. Res., 104, 14,309-14,319.

Moulin, C., F. Guillard, F. Dulac, and C. E. Lambert (1997), Long-term daily monitoring of Saharan dust load over ocean using Meteosat ISCCPB2 data: 1. Methodology and preliminary results for 1983-1994 in the Mediterranean, J. Geophys. Res., 102, 16,947-16,958.

Perlwitz, J., I. Tegen, and R. Miller (2001), Interactive soil dust aerosol model in the GISS GCM part I: Sensitivity of the soil dust cycle to radiaitive properties of dust aerosols, J. Geophys. Res., 106, 18,16718,192 .

Prospero, J. M. (1996), The atmospheric transport of particles to the ocean, in Particle Flux in the Ocean, edited by V. Ittekot et al., John Wiley, Hoboken, N. J.

Prospero, J. M., and T. N. Carlson (1972), Vertical and areal distribution of Saharan dust over the western equatorial North Atlantic Ocean, J. Geophys. Res., 77, 5255-5565.

Rasch, P. J., and M. Lawrence (1998), Recent development in transport methods at NCAR in MPI Workshop on Conservative Transport Schemes, edited by B. Machenhauer et al., Rep. 265, Max-Planck-Inst. für Meteorol., Hamburg, Germany.

Roeckner, E., K. Arpe, L. Bengtsson, M. Christoph, M. Claussen, L. Dümenil, M. Esch, M. Giorgetta, U. Schlese, and U. Schulzweida (1996), The atmospheric general circulation model ECHAM-4: Model description and simulation of the present-day climate, Rep. 218, Max-Planck-Inst. für Meteorol., Hamburg, Germany.

Schulz, M., Y. Balkanski, W. Guelle, and F. Dulac (1998), Role of aerosol size distribution and source location in a three-dimensional simulation of a Saharan dust episode tested against satellite-derived optical thickness, J. Geophys. Res., 103, 10,579-10,592.

Sokolik, I., and O. B. Toon (1996), Dust radiaitve forcing by anthropogenic airborne mineral aerosols, Nature, 381, 681-683.

Tegen, I., and A. A. Lacis (1996), Modeling of particle size distribution and its influence on the radiative properties of mineral dust aerosol, J. Geophys. Res., 101, 19,237-19,244.

Tegen, I., P. Hollrig, M. Chian, I. Fung, D. Jacob, and J. Penner (1997), Contribution of different aerosol species to the global aerosol extinction optical thickness: Estimates from models results, J. Geophys. Res., 102, 23,895-23,915

Tegen, I., S. P. Harrison, K. Kohfeld, I. C. Prentice, M. Coe, and M. Heimann (2002), Impact of vegetation and preferential source areas on global dust aerosols: Results from a model study, J. Geophys. Res., 107(D21), 4576, doi:10.1029/2001JD000963.

Timmreck, C., and M. Schulz (2003), Interannual variability of sea salt simulated with a general circulation model, J. Aerosol, 543-544.

Underwood, G. M. C. H. Song, M. Phadnis, G. R. Carmichael, and V. H. Grassian (2001), Heterogeneous reactions of $\mathrm{NO}_{2}$ and $\mathrm{HNO}_{3}$ on oxides and mineral dust: A combined laboratory and modeling study, J. Geophys. Res., 106, 18,055-18,066.

Werner, M., I. Tegen, S. P. Harrison, K. E. Kohlfeld, I. C. Prentice, Y. Balkanski, H. Rohde, and C. Roelandt (2002), Seasonal and interannual variability of the mineral dust cycle under present and glacial climate conditions, J. Geophys. Res., 107(D24), 4744, doi:10.1029/ 2002JD002365.

Woodward, S. (2001), Modeling the atmospheric cycle and radiative impact of mineral dust in the Hadley Centre climate model, J. Geophys. Res., $106,18,155-18,166$.

Wurzler, S., T. G. Reisin, and Z. Levin (2000), Modification of mineral dust particles by cloud processing and subsequent effects on drop size distributions, J. Geophys. Res., 105, 501-512.

Zender, C. S., H. Bian, and D. Newman (2003), Mineral Dust Entrainment and Deposition (DEAD) model: Description and 1990s dust climatology, J. Geophys. Res., 108(D14), 4416, doi:10.1029/2002JD002775.

M. Schulz, Sciences du Climat et de 1 Environnement, CEA/CNRS LSCE, Orme des Merisiers, Bat. 709, F-91191 Gif-sur Yvette Cedex, France. (schulz@1sce.saclay.cea.fr)

C. Timmreck, Max-Planck Institut für Meteorologie, Bundesstr. 55, D-20146 Hamburg, Germany. (timmreck@dkrz.de) 